\title{
Decoding the learning curve of non-descent vaginal hysterectomy in the era of laparoscopy- experience at a Zonal Hospital
}

\author{
Shikha Sharma ${ }^{1 *}$, Jafar Husain ${ }^{2}$, Anshul Jain², Sruthi Bhaskaran ${ }^{1}$, Raj Singh ${ }^{3}$, Kavita Pandey ${ }^{1}$
}

\author{
${ }^{1}$ Department of Obstetrics and Gynecology, Military Hospital, Agra, Uttar Pradesh, India \\ ${ }^{2}$ Department of General Surgery, Military Hospital, Agra, Uttar Pradesh India \\ ${ }^{3}$ Department of Pathology, Military Hospital, Agra, Uttar Pradesh, India
}

Received: 15 March 2021

Accepted: 13 April 2021

\author{
*Correspondence: \\ Dr. Shikha Sharma, \\ E-mail: shikhalhmc@gmail.com
}

Copyright: (C) the author(s), publisher and licensee Medip Academy. This is an open-access article distributed under the terms of the Creative Commons Attribution Non-Commercial License, which permits unrestricted non-commercial use, distribution, and reproduction in any medium, provided the original work is properly cited.

\begin{abstract}
Background: Despite of the increasing popularity of laparoscopic hysterectomy, vaginal route still stays pertinent. Non descent vaginal hysterectomy (NDVH) involves d steep learning curve and hence, should be a fundamental part of every Gynaecology residency program. Objective of the study was to assess the learning curve of NDVH surgery skill at a Military Zonal Hospital by a single Specialist over a period of two years.

Methods: Retrospective study conducted at Military Hospital, Agra between June 2015 to June 2017 on 30 patients who underwent NDVH for benign gynaecological conditions.

Results: The average blood loss was noted to reduce from a mean of $285 \mathrm{ml}( \pm 108.94)$ in the first 20 cases (Group 1) to $227 \mathrm{ml}( \pm 110.89)$ in the next 10 cases (Group 2) despite of the average uterine size increasing from $8.5( \pm 1.43)$ weeks in Group 1 to $10.2( \pm 2.39)$ weeks in Group 2. The average time taken in minutes was also seen to reduce from $89.75( \pm 12.62)$ in Group 1 to $70.5( \pm 16.50)$ in Group 2 indicating an improvement of surgical skills. The average 24 $\mathrm{hr}$ post-operative haemoglobin fall of $0.8 \mathrm{gm} \%$ was similar between the two groups.

Conclusions: Acquiring NDVH skills is a slow but rewarding process. NDVH involves no incisions, no elaborate setup, avoids complications of general anaesthesia and pneumo-peritoneum and displays similar results as of laparoscopy. In limited resource countries vaginal route may be the only available minimally invasive option for hysterectomy. Hence, it's pertinent that Gynecologists are trained in the same.
\end{abstract}

Keywords: Hysterectomy, Learning curve, Non-descent, Surgical skill

\section{INTRODUCTION}

Hysterectomy is the second most common surgery performed by gynaecologists after caesarean sections. ${ }^{1-3}$ This surgery can be accomplished by a variety of techniques and approaches, including abdominal, vaginal, laparoscopic and robotic.

The decision regarding the route of hysterectomy for benign causes depends on the vaginal space, uterine size and shape, extent of extrauterine pathology, anticipated concurrent procedures, surgical training and experience, available hospital infrastructure as well as patient preference.

The abdominal route is most popular when dealing with large uteri, ovarian and other gynaecological malignancies. However, the abdominal surgery results in higher intra-operative blood loss, hectic post-operative period in terms of longer hospital stay, larger haemoglobin drop and greater incidences of wound or abdominal wall infections. Ample evidence has shown that the vaginal route of hysterectomy results in lower morbidity, lesser post-operative pain, faster recovery with more rapid return to normal activity with no requirement 
of any special staff, equipment or infrastructure as compared to the laparoscopic route. ${ }^{4}$

Despite of the roaring popularity of laparoscopic surgery, non-descent vaginal surgery still has a distinct place in Gynaecology with notable advantages even over the minimally invasive route.

Vaginal surgery especially non-descent hysterectomy requires precision and sharp surgical skills. If learnt well, it is also, a confidence building exercise which is a stepping stone to any advance surgical skill that the surgeon may later venture into. Therefore, training in vaginal surgery should be an indispensable constituent of residency programs, even in the most advanced settings.

\section{METHODS}

This was a retrospective study conducted in the department of Obstetrics and Gynaecology, Military Hospital, Agra between June 2015 to June 2017 after Ethical Committee approval. Records of all the patients who had undergone non descent vaginal surgery during this period were reviewed in terms of their age, indication for surgery, uterine size, intra-operative blood loss, postoperative recovery and any complications.

\section{Inclusion criteria}

All the patients who had no cervico-uterine prolapse and underwent non-descent vaginal hysterectomy for benign conditions.

At the time of surgery, patients were carefully selected according to the selection criteria, uterine size not more than 12 weeks, adnexal pathology ruled out, freely mobile uterus, definitive benign conditions e.g. AUB, fibroid, adenomyosis and genital malignancy ruled out.

\section{Exclusion criteria}

Patients with cervico-uterine prolapse requiring vaginal hysterectomy with pelvic floor repair. At the time of surgery, patients were carefully selected according to the selection criteria, uterine size more than 12 weeks, adnexal pathology, restricted uterine mobility, fixed or pulled up cervix and genital malignancy. Clinical assessment for feasibility of vaginal surgery was effectuated through the following criteria.

Vaginal inaccessibility: Inter-tuberous diameter less than $9 \mathrm{~cm}$ along with a subpubic angle of less than 900 and a vagina of less than two finger caliber, pulled up or fixed cervix was ruled out and uterine volume and mobility: If expanded more in transverse diameter anticipated to cause more intra-operative trouble.

Written informed consent was taken from all the patients regarding the surgery, route of surgery, conversion to abdominal hysterectomy in case required and also, bladder and rectal injury. Age, uterine size and endometrial histopathology were noted pre-operatively. Patients were re-examined under anaesthesia for uterine size, mobility, vaginal space as well as vaginal and cervical accessibility.

Cervix was held with tenaculum and the left and right lateral angles with Allis forceps. Dissection was initiated with liberal infiltration of the sub-mucosal space with normal saline. This infiltration facilitated hydrodissection, made the point of incision clearer anteriorly and posteriorly and also, reduced intra-operative bleeding. Bladder was separated from uterus by sharp dissection in the pubo-vesico-cervical fascia and the vesico-vaginal space opened. In case of difficulty encountered while separating and mobilizing the bladder, the posterior pouch was opened first followed by the opening of the anterior space. First clamp included uterosacral and Mackenrodt's ligaments followed by opening of the utero-vesical pouch. Thereafter, uterine arteries were clamped, cut and ligated followed by clamping and cutting of the cornual structures. All the stumps were checked for bleeding and haemostasis ensured. Vault was closed by continuous interlocking suture using Vicryl No.1 suture. Operating time was calculated in minutes. Estimation of blood loss was done by counting the number of mops used during surgery and amount of blood in suction bottle. Any postoperative complications were recorded. All cases were done with routine instruments required for vaginal hysterectomy.

\section{Statistical analysis}

The data was analysed using the Microsoft Excel software. Descriptive statistics like mean and percentage were used to interpret data with the help of Microsoft Office 2007.

\section{RESULTS}

A total of 30 patients underwent non-descent vaginal hysterectomy between June 2015 to June 2017 after careful selection.

Table 1: Indications of surgery.

\begin{tabular}{|ll|}
\hline Indications & $\%(\mathrm{n})$ \\
\hline Post-menopausal bleeding & $3.3(\mathrm{n}=1)$ \\
\hline AUB- L & $23.3(\mathrm{n}=7)$ \\
\hline AUB-M & $23.3(\mathrm{n}=7)$ \\
\hline AUB-A & $20(\mathrm{n}=6)$ \\
\hline AUB-O & $16.6(\mathrm{n}=5)$ \\
\hline Leiomyoma & $6.6(\mathrm{n}=2)$ \\
\hline Adenomyosis & $6.6(\mathrm{n}=2)$ \\
\hline
\end{tabular}

The average age of the patients was 43.9 years with one post-menopausal patient amongst them. The most common indication was AUB-L and AUB-M seen in $23.3 \%(n=7)$ women each followed by AUB-A in $20 \%$ 
$(n=6), \quad$ AUB-O in $16.6 \% \quad(n=5)$, leiomyoma and adenomyosis in $6.6 \%(n=2)$ each while post-menopausal bleeding was seen in only one patient and in that case malignancy had been conclusively ruled out (Table 1).

The average pre-operative haemoglobin was $11.12 \mathrm{gm} \%$ ranging from $10 \mathrm{gm} \%$ - $12.8 \mathrm{gm} \%$. Pre-operative endometrial histopathology revealed proliferative endometrium in $36.6 \%(\mathrm{n}=11)$, secretory endometrium in $26.7 \%(n=8)$, simple hyperplasia in $33.3 \%(n=10)$ while atrophic endometrium was detected in $3.3 \% \quad(n=1)$ patient. The average pre-operative haemoglobin was $11.12 \mathrm{gm} \%$ ranging from $10 \mathrm{gm} \%-12.8 \mathrm{gm} \%$ (Table 2).

Table 2: Comparison of pre-operative and postoperative histopathology.

\begin{tabular}{|c|c|}
\hline Pre-op HPE \% (n) & Post-op HPE \% (n) \\
\hline Senile $3.3(n=1)$ & Fibroid $3.3(n=1)$ \\
\hline $\begin{array}{l}\text { Simple } \\
\text { hyperplasia } 33.3 \\
(n=10)\end{array}$ & $\begin{array}{l}\text { Fibroid with simple hyperplasia } \\
3.3(n=1)\end{array}$ \\
\hline $\begin{array}{l}\text { Secretory } 26.6 \\
(n=8)\end{array}$ & $\begin{array}{l}\text { Fibroid with secretory } \\
\text { endometrium } 3.3(n=1)\end{array}$ \\
\hline \multirow{8}{*}{$\begin{array}{l}\text { Proliferative } 36.6 \\
(n=11)\end{array}$} & $\begin{array}{l}\text { Adenomyosis with lymphocyte } \\
\text { infiltration } 3.3(n=1)\end{array}$ \\
\hline & Adenomyosis $6.6(\mathrm{n}=2)$ \\
\hline & $\begin{array}{l}\text { Adenomyosis with proliferative } \\
\text { endometrium } 6.6(\mathrm{n}=2)\end{array}$ \\
\hline & $\begin{array}{l}\text { Proliferative endometrium } 6.6 \\
(\mathrm{n}=2)\end{array}$ \\
\hline & $\begin{array}{l}\text { Adenomyosis with secretory } \\
\text { endometrium } 10(n=3)\end{array}$ \\
\hline & $\begin{array}{l}\text { Adenomyosis with hyperplasia } \\
13.3(n=4)\end{array}$ \\
\hline & $\begin{array}{l}\text { Fibroid with proliferative } \\
\text { endometrium } 13.3(\mathrm{n}=4)\end{array}$ \\
\hline & Simple hyperplasia $26.6(n=8)$ \\
\hline
\end{tabular}

The patients who had even mild anaemia in the preoperative period were built up to at least $10 \mathrm{gm} \%$ with oral haematinics with no patient requiring blood transfusion for the same. Pre-operative endometrial histopathology revealed proliferative endometrium in $46.7 \%$, secretory endometrium in $26.7 \%$ and simple hyperplasia in $26.7 \%$. The average blood loss intraoperatively was $265.67 \mathrm{ml}$ ranging from $100 \mathrm{ml}$ to $500 \mathrm{ml}$ and the average time taken was 83.33 minutes ranging from 50- 120 minutes.

Table 3: Comparison of variables between group 1 (first 20) and group 2 (last 10).

\begin{tabular}{|lll|}
\hline Variables & First 20 & Last 10 \\
\hline Average time taken (mins) & 89.75 & 70.5 \\
\hline Average blood loss (ml) & 285 & 227 \\
\hline $\begin{array}{l}\text { Average uterine size } \\
\text { (weeks) }\end{array}$ & 8.2 & 10.2 \\
\hline Average Hb fall (gm\%) & 0.8 & 0.8 \\
\hline
\end{tabular}

It was also observed that the blood loss was proportional to the time taken and the uterine size. The largest uterine size operated on was 14 weeks seen in two patients. Bisection, coring and myomectomy were utilized to facilitate uterine extraction with solely bisection used in nine patients, bisection with myomectomy used in four patients, myomectomy in one patient and myomectomy with coring utilized in the two patients with uterine size of 14 weeks. The mean blood loss was seen to reduce from a mean of $285 \mathrm{ml}$ in group 1 to $227 \mathrm{ml}$ in group 2 despite of the average uterine size increasing from 8.2 weeks to 10.2 weeks respectively. The average time taken in minutes was also seen to reduce from 89.75 in group 1 to 70.5 in group 2 (Table 3, Figure 1, 2, 3).

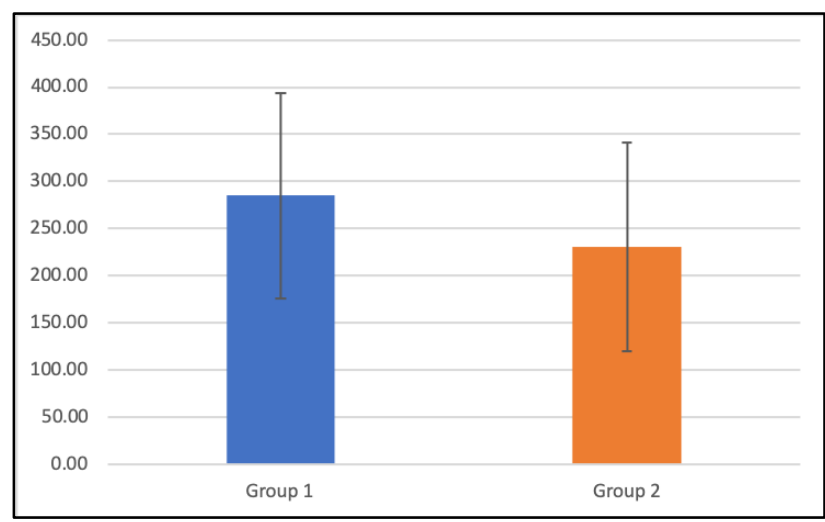

Figure 1: Comparison of mean blood loss.

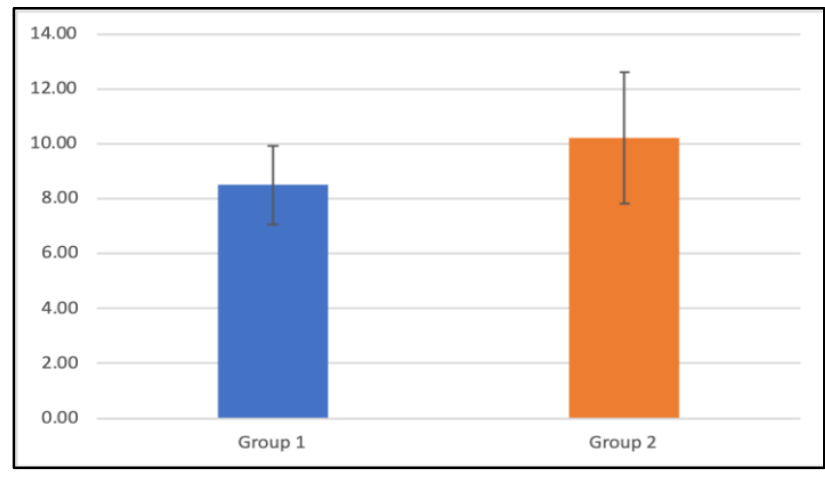

Figure 2: Comparison of uterine size.

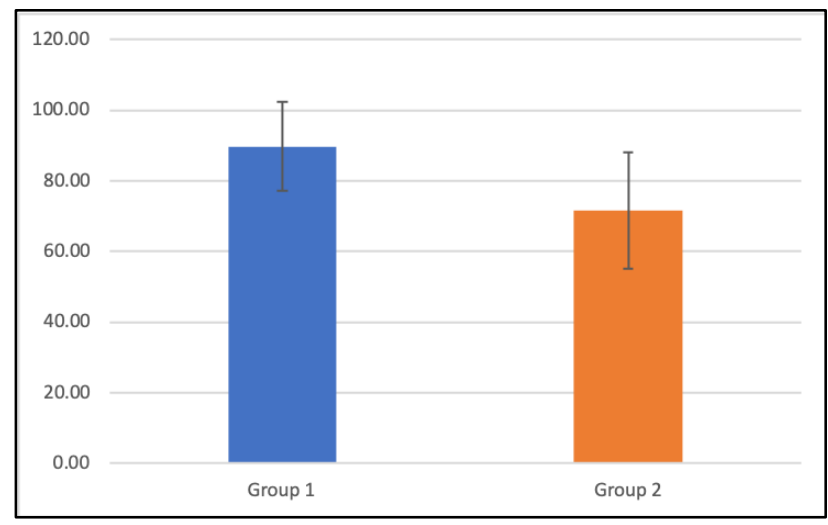

Figure 3: Comparison of total time taken. 
The average haemoglobin after 24 hours post-operatively was $10.3 \mathrm{gm} \%$ showing an average fall of $0.81 \mathrm{gm} \%$. Despite of the increasing uterine size and increasing operative difficulty being dealt with, the mean haemoglobin fall of $0.81 \mathrm{gm} \%( \pm 0.361)$ in Group 1 and $0.81 \mathrm{gm} \%( \pm 0.407)$ in group 2 was identical (Figure 4$)$.

Patients, on an average, were admitted for 3.5 days ranging from 3-5 days. Post-operative fever was noted in four patients, two of whom also experienced spotting along with the same. Although, fever subsided within $36 \mathrm{hrs}$ but spotting persisted for 3-4 weeks. In one of these two patients. A haematoma of $2 \mathrm{~cm}$ just above the vault was noted on TVS at the 4 week visit and was subsequently, put on tranexamic acid and responded well.

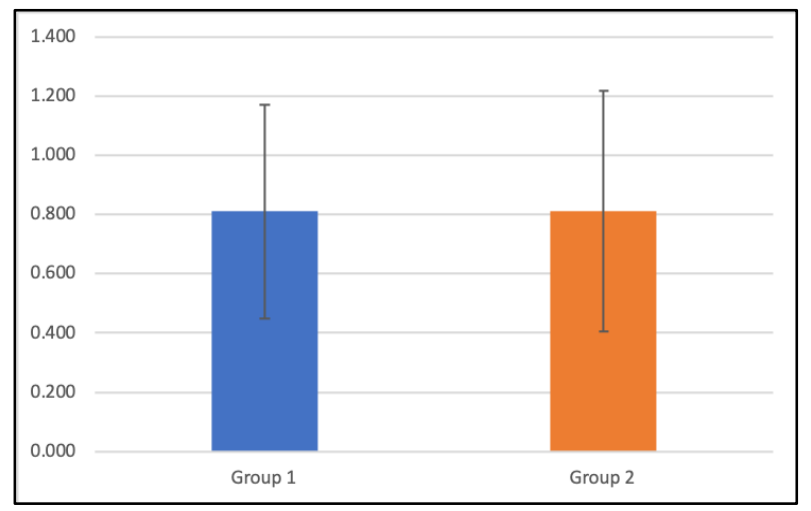

Figure 4: Comparison of mean haemoglobin fall.

On histopathological examination of the specimens, there was fibroid with simple hyperplasia, fibroid with secretory endometrium and fibroid alone in one patient each. One patient was found to have adenomyosis with lymphocytic infiltration. Two patients each had adenomyosis, adenomyosis with proliferative endometrium and proliferative endometrium alone. Three patients had adenomyosis with secretory endometrium, four had adenomyosis with simple hyperplasia, four had fibroid with proliferative endometrium while simple hyperplasia was seen in eight patients.

\section{DISCUSSION}

Hysterectomies are, by far, the most common elective surgeries performed in gynaecology with abdominal, vaginal, laparoscopy and robotics holding their own. Despite of laparoscopic route of surgery gaining widespread popularity and laparoscopic training being integrated into residency programs world over, NDVH continues to have a niche status amongst gynaecological surgeons. ${ }^{5}$ It is not wrong to say that residency programs may or may not have laparoscopy training but training in vaginal surgery is still an indispensable part of Gynaecology residency curriculum.

The route of hysterectomy depends on the patient's clinical findings and pathology, available infrastructure and surgeon's experience. There are notable differences in the medical and economic outcomes of abdominal, vaginal, laparoscopic and robotic hysterectomies and in that case, standard of appropriate care should be applied when deciding on the route of surgery for an individual patient. ${ }^{6}$ The common limitations of non- descent vaginal hysterectomy include large uterine size, nulliparity, previous pelvic surgery or lower segment caesarean section, pelvic adhesions, endometriosis and most importantly, limited exposure during the learning phase of surgical carrier.

The mean age of patients in our study was $43.9 \mathrm{yrs}$ which corresponded with the mean age of $41.44 y$ rs as observed by Sandhyasri $\mathrm{P}$ et al, in their comparative study between abdominal, non-descent vaginal and laparoscopic hysterectomies and as also, by most of the studies in literature. The most common indication in our study, as noted in $43.3 \%$ cases, was AUB-M similar to the one reported by Suhas Shinde et al. However, Dewan et. al and Uikey et al observed that fibroid uterus led to NDVH in most of the cases. ${ }^{7,8}$

The mean blood loss was $265.67 \mathrm{ml}$ and was seen to reduce from a mean of $285 \mathrm{ml}$ in the first 20 cases to $227 \mathrm{ml}$ in the next 10 cases despite of the average uterine size increasing from 8.2 weeks in the first 20 cases to 10.2 weeks in the last 10 cases. The average time taken in minutes was also seen to reduce from 89.75 in the first 20 to 70.5 in the next 10 cases suggesting a gradual and steady improvement in the surgical skill. This corresponded to the findings projected by $\mathrm{S}$ Shanthi et al. ${ }^{9-12}$ The mean overall haemoglobin fall noted was $0.81 \mathrm{gm} \%$ and it was the same between the first 20 and the last 10 cases despite of the increasing complexity of cases being dealt with, indicating that a gradual improvement in the surgical skill. There was neither any bladder injury nor any conversion to abdominal hysterectomy (Table 3).

The lessons learnt were thorough pre-operative work up and clinical examination.

Take care of ergonomics, Patient placed in lithotomy position and at the edge of the OT table, atient's legs to be abducted to such an extent that the first apnd second assistants can stand between them, avoiding excessive external rotation at the hip joints and height of the table OT table adjusted such that the surgeon's arms are comfortably adducted at the shoulders and flexed at the elbow to about $90^{\circ}-100^{\circ}$, with his head slightly flexed. "A comfortable surgeon demonstrates better surgical acumen".

Liberal infiltration with either plain saline or that with adrenaline in ratio of $1: 10$. I personally only used plane saline and hardly encountered any disturbing intraoperative blood loss. After the initial circumoral incision, use blunt dissection to open anterior and posterior pouches. In case of adhesions, resort to sharp dissection 
taking small tissue bits. Instead of struggling with difficult bladder dissection anteriorly, proceed from the posterior pouch first in difficult cases.

Lift, check, cross-check before cutting any tissue. What is more important is to note "what is underneath" of whatever that we are dealing with judicious use of electro-surgery preferring to suture wherever possible. Limited visibility may lead to inadvertent injuries. Bisect the uterus instead of struggling with space constraints. Halving the size doubles the space.

Ensure haemostasis before closing the vault. Do not forget to take McCall's sutures in case of elderly and those with lax vaginal tissues to reduce the future risk of vault prolapse.

\section{CONCLUSION}

Non-descent vaginal surgery is an "art", acquiring which should be an indispensable part of all residency curriculums. Vaginal surgeries take time and patience to learn but the dissection skills that they confer are unmatched and are an important stepping stone to more complex surgeries.

\section{Funding: No funding sources}

Conflict of interest: None declared

Ethical approval: The study was approved by the Institutional Ethics Committee

\section{REFERENCES}

1. Rock, John A, Howard W. Jones III. TeLinde's Operative Gynecology. New Delhi: Wolters Kluwer (India) Pvt. Ltd., Eleventh edition. Chap 32A, 697.

2. Asgari Z, Bahreini F, Samiee H, Eslami B, Tehranian A, Sabet S. Comparison of laparoscopically assisted vaginal hysterectomy and total abdominal hysterectomy. Med J Islamic Repub Iran (MJIRI). 2008;22(1):22-8.

3. Moradan S, Sayadiou S. Hospital based analysis of 204 cases of hysterectomies with evaluation of the route of surgery and complications rates. Southeast Asian J Case Report Review. 2014;3(6):1060-6.

4. Choosing the route of hysterectomy for benign diseases. ACOG Committee Opinion No 444. American college of Obstetricians and Gynecologists. Obstet Gynecol. 2009;114:156-8.

5. Deshpande H, Burute S, Malik R. A comparative study of abdominal versus non descent vaginal hysterectomy. Int J Cont Med Res. 2016;3(4):11536.

6. Kovac R. Evidence based hysterectomy. Gynecol Obstet. 2013;3(4):1153-6.

7. Dewan R, Agarwal S, Minocha B, Sen SK. Nondescent vaginal hysterectomy -an experience. J Obstet Gynecol India. 2004;54(4):376-8.

8. Uikey P Wankhede TM, Tajne MP. Int J Reprod Contracept Obstet Gynecol. 2018;7(10):4022-8

9. Shanthi s, Rani SU, Arumaikannu J. Feasibility of non-descent vaginal hysterectomy (NDVH) in women with scarred uterus- our experience. Int $\mathbf{J}$ Clin Obstet Gynecol. 2017;1(2):76-9.

10. Bharatnur S. Comparative study of abdominal versus vaginal hysterectomy in Non-Descent cases. Internet J Gynaecol Obstet. 2011;15(2):1528-39.

11. Bhadra B, Choudary AP, Tolassaria A, Nupur N. Non-descent vaginal hysterectomy (NDVH): personal experiences in 158 cases. AL Ameen J Med Sci. 2011;4(1):23-7.

12. Kumar N, Tayade S. Role of non-descent vaginal hysterectomy in previous cesarean section scar women. Int J Reprod Contracept Obstet Gynecol. 2015;4:785-9.

Cite this article as: Sharma S, Husain J, Jain A, Bhaskaran S, Singh R, Pandey K. Decoding the learning curve of non-descent vaginal hysterectomy in the era of laparoscopy- experience at a Zonal Hospital. Int J Reprod Contracept Obstet Gynecol 2021;10:2015-9. 